\title{
YM155 Reverses Statin Resistance in Renal Cancer by Reducing Expression of Survivin
}

\author{
TAKASHI NITTA, HIDEKAZU KOIKE, TAKESHI MIYAO, YOSHIYUKI MIYAZAWA, \\ HARUO KATO, YOSUKE FURUYA, YOSHITAKA SEKINE and KAZUHIRO SUZUKI \\ Department of Urology, Gunma University Graduate School of Medicine, Maebashi, Japan
}

\begin{abstract}
Aim: The purpose of the present study was to clarify whether treatment with YM155, a novel small-molecule inhibitor of survivin, reverses statin resistance in statinresistant renal cell cancer (RCC). Materials and Methods: We induced simvastatin resistance in a renal clear cell carcinoma cell line (Caki-1-staR). In vitro and in vivo models were used to test the efficacy of YM155 and simvastatin. Results: Survivin gene expression was significantly stronger in Caki1-staR cells than in its parent cells (Caki-1). In Caki-1-staR cells, YM155 significantly reduced expression of survivin gene and cell proliferation in a dose-dependent manner. Treatment with YM155 significantly reversed simvastatin resistance in Caki-1-staR cells. YM155 significantly inhibited the growth of Caki-1-staR tumors in a nude mouse tumor xenograft model. Furthermore, YM155 significantly enhanced the antitumor effects of simvastatin on Caki-1-staR tumors. Conclusion: Our results indicate that inhibition of survivin by YM155 overcomes statin resistance in RCC cells.
\end{abstract}

Statins are a family of 3-hydroxy-3-methylglutaryl coenzyme A (HMG CoA) reductase inhibitors that are used to treat hyperlipidemia. Statins have recently been reported to exert anticancer effects on various cancer cells, including breast (1-3), hepatic (4), colon (5, 6), and renal (7) cancer. We previously reported that simvastatin inhibited insulin-like growth factor 1 (IGF1)/insulin-like growth factor 1 receptor (IGF1R) signaling in prostate cancer by reducing the expression of IGF1R in PC-3 cells, which resulted in

This article is freely accessible online.

Correspondence to: Associate Professor Hidekazu Koike, Department of Urology, Gunma University Graduate School of Medicine, 3-39-22 Showa-Machi, Maebashi 371-8511, Japan. Tel: +81272208300, Fax: +81 272208318, e-mail: hkoike@gunmau.ac.jp

Key Words: Kidney neoplasms, inhibitor of apoptosis proteins, statin, drug therapy, combination. inhibition of cell proliferation in vitro (8). Although a large number of patients with cancer receive therapeutic agents, the development of resistance ultimately results in treatment failure. Accordingly, the molecular mechanisms contributing to drug resistance need to be elucidated in greater detail in order to identify novel therapeutic targets for cancer.

Survivin, a member of the inhibitors of apoptosis protein family (9), is selectively expressed in most common human neoplasms (10). The up-regulation of survivin has been correlated with an advanced grade of carcinoma (11) and poor patient survival in several cancer types, including colorectal (12) and non-small cell lung cancer (13). Furthermore, increasing evidence suggests that the expression of survivin is associated with drug resistance in cancer cells and cancer-associated endothelial cells (14-19).

YM155, a novel small-molecule inhibitor of survivin, was identified by cell-based high-throughput screening (20). YM155 suppresses the transactivation of survivin by directly binding to its promoter (21). Cheng et al. reported that YM155 inhibited the expression of survivin at least in part through its inhibition of survivin transcription via the disruption of SP1 interaction with the region of -149 to -71 in the survivin core promoter (22). YM155 exhibited potent antitumor activity in vitro and induced tumor regression in established xenografts of hormone-refractory prostate cancer (20), non-Hodgkin's lymphoma (23), non-small cell lung cancer (24) and melanoma (25). Furthermore, the safety and tolerability of YM155 have been demonstrated in phase I and phase II trials on patients with advanced refractory non-small cell lung carcinoma (26) and unresectable melanoma (27). In xenograft models, the anticancer efficacy of YM155 in combination with docetaxel (28) or platinum compounds (29) was found to be superior to that of monotherapy $(20,30)$. We previously reported that YM155 reversed rapamycin resistance in renal cancer by reducing survivin expression in vitro and in vivo (31).

This study was intended as an investigation of the efficacy of YM155 and of whether treatment with YM155 reverses statin resistance in a statin-resistant renal clear cell carcinoma cell line (Caki-1-staR) with acquired statin resistance both in vitro and in vivo. 


\section{Materials and Methods}

Cells and chemicals. The human renal cancer cell line, Caki-1, was purchased from the Japan Health Sciences Foundation (Tokyo, Japan) and cultured in minimal essential medium (MEM) (Invitrogen, Carlsbad, CA, USA) supplemented with fetal bovine serum (FBS; Moregate, Bulimba, Australia).

3-(4,5-Dimethylthiazol-2-yl)-5-(3-carboxymethoxyphenyl)-2-(4sulphophenyl)-2H-tetrazolium, inner salt (MTS) was purchased from Promega (Madison, WI, USA). Small interfering ribonucleic acid (siRNA) for survivin (HP Validated siRNA) was purchased from Qiagen (Valencia, CA, USA) (survivin no. SI00299453 and negative control no. 1027310). HP Validated siRNA is predesigned siRNA that has been functionally tested for knockdown efficiency by a quantitative reverse transcription polymerase chain reaction (RT-PCR). YM155 was obtained from Selleck Chemicals (Houston, TX, USA). Simvastatin was purchased from Calbiochem (San, Diego, CA, USA) and Sigma (St. Louis, MO, USA). BALB/c-nu/nu mice (male, 5 weeks old) was purchased from Charles River Laboratories (Yokohama, Japan). Matrigel was obtained from BD Biosciences (Tokyo, Japan). A rabbit polyclonal antibody to survivin (no. NB100-56167) was obtained from Novus Biologicals (Littleton, CO, USA).

Induction of simvastatin resistance in the renal cancer cell line. Caki-1 cells were initially cultured in MEM containing $100 \mathrm{nM}$ simvastatin and the cells that proliferated were repeatedly subcultured in MEM containing increasing concentrations of simvastatin over a 3 -month period. Cells that grew in $10 \mu \mathrm{M}$ simvastatin were designated as Caki-1-staR.

Cell proliferation assay. The number of living cells was measured using the CellTiter $96{ }^{\circledR}$ AQueous One solution cell proliferation MTS assay according to the manufacturer's instructions. A total of $3 \times 10^{3}$ Caki-1-staR cells were incubated with different concentrations of simvastatin $(\mu \mathrm{M})$ with/without YM155 (nM) in modififesd Eagle's medium with 1\% FBS and antibiotics (penicillin and streptomycin) for periods at $37^{\circ} \mathrm{C}$ in a $5 \% \mathrm{CO}_{2}$ atmosphere. siRNA (for survivin or negative control) and HiPerFect Transfection Reagent (Qiagen) were used according to the manufacturer's protocol.

Xenograft model. In order to evaluate the effects of simvastatin with/without YM155 on simvastatin-resistant renal tumor growth in vivo, we used a nude mouse tumor xenograft model. Mice (6 weeks old) were transplanted subcutaneously with $2.5 \times 10^{6}$ Caki-1-staR cells mixed with $100 \mu \mathrm{l}$ of Matrigel and $100 \mu \mathrm{l}$ of phosphate buffered saline (PBS) into the right flank. Palpable tumors developed at the injection sites. The mean tumor volume at 13 weeks old was $183 \mathrm{~mm}^{3}$ (Caki-1-staR) using the following equation: $\mathrm{m}_{1}^{2} \times \mathrm{m}_{2} \times 0.5236$, where $\mathrm{m}_{1}$ represents the short axis and $\mathrm{m}_{2}$ the long axis. Mice were then stratified into different groups $(n=4)$ such that mean tumor volumes in each group were similar. Every 3 days, animals were treated with simvastatin $(20 \mathrm{mg} / \mathrm{kg})$ or YM155 (3 mg/kg) or PBS via intraperitoneal injections. Tumor volume measurements began on day 7 and continued twice a week until the end of the study. After 29 days, mice were sacrificed by cervical dislocation, and primary tumors were carefully removed, photographed, and analyzed for survivin mRNA expression and immunohistochemical staining. The present study was approved by the Gunma University Animal Care and Experimentation Committee (approval number; 15-042).

Tumor hematoxylin-eosin and immunohistochemical staining. An immunohistochemical study was performed using the labeled streptavidin biotin method with a rabbit polyclonal antibody to survivin at a 1:3,000 dilution. Secondary biotinylated anti-rabbit IgG (Vector Laboratories, Burlingame, CA, USA) was used at a 1:800 dilution. All specimens were blindly examined pathologically by a single doctor to confirm immune stainability.

Quantitative real time polymerase chain reaction (RT-PCR) analysis. We extracted total RNA from cells after treatment and isolated tumor tissue, and reverse-transcribed it for complementary deoxyribonucleic acid (cDNA). Transcript levels were quantified using an ICycler IQ ${ }^{\mathrm{TM}}$ system (Hercules, CA, USA) according to the manufacturer's instructions. Amplification was performed in 10 $\mu \mathrm{l}$ of Premix Ex $\mathrm{Taq}^{\mathrm{TM}}$ using $2 \mu \mathrm{l}$ of cDNA and a survivin primer (forward, 5'-CCA CCG CAT CTC TAC ATT CA; reverse, 5'-TAT GTT CCT CTA TGG GGT CG). PCR was performed for 1 cycle at $95^{\circ} \mathrm{C}$ for $10 \mathrm{~min}$, followed by 40 cycles at $95^{\circ} \mathrm{C}$ for $15 \mathrm{sec}$ and $60^{\circ} \mathrm{C}$ for $60 \mathrm{sec}$. Levels of $18 \mathrm{~S}$ rRNA transcript (18S rRNA forward, 5'CGG CTA CCA CAT CCA AGG AA; reverse, 5'-GCT GGA ATT ACC GCG GCT GC) were used as the internal control. Gene expression is shown as fold change vs. expression of controls.

Statistical analysis. Data are expressed as the mean \pm SD. Student's $t$-test was used for single comparison of two groups. Differences between values in the simvastatin and YM155 experiments were evaluated by ANOVA using Tukey's post-hoc analysis. ANOVA was also used to compare tumor sizes in mice after the different treatments. In all analyses, a value of $p<0.05$ was considered to be significant.

\section{Results}

Survivin expression in the statin-resistant renal cancer cell line. The viability of Caki-1 cells was significantly inhibited by 1 and $10 \mu \mathrm{M}$ simvastatin (Figure 1A).

The survivin mRNA level was significantly higher in Caki-1-staR cells than that in its parental cell line Caki-1 (Figure 1B).

YM155 significantly down-regulates survivin gene expression and enhances the antiproliferative effects of simvastatin treatment in simvastatin-resistant renal cancer cells. The inhibition of survivin by siRNA in Caki-1-staR cells significantly reversed simvastatin resistance in these cells as shown by their reduced viability (Figure 1C). We investigated whether YM155 inhibits survivin expression in Caki-1-staR cells in vitro. YM155 significantly inhibited survivin mRNA expression in a dose-dependent manner (Figure 1D). Caki-1-staR cell proliferation was also inhibited by YM155 in a dose-dependent manner in the MTS assay (Figure 1E). In addition, YM155 significantly enhanced the antiproliferative effects of simvastatin treatment (Figure 1F). 

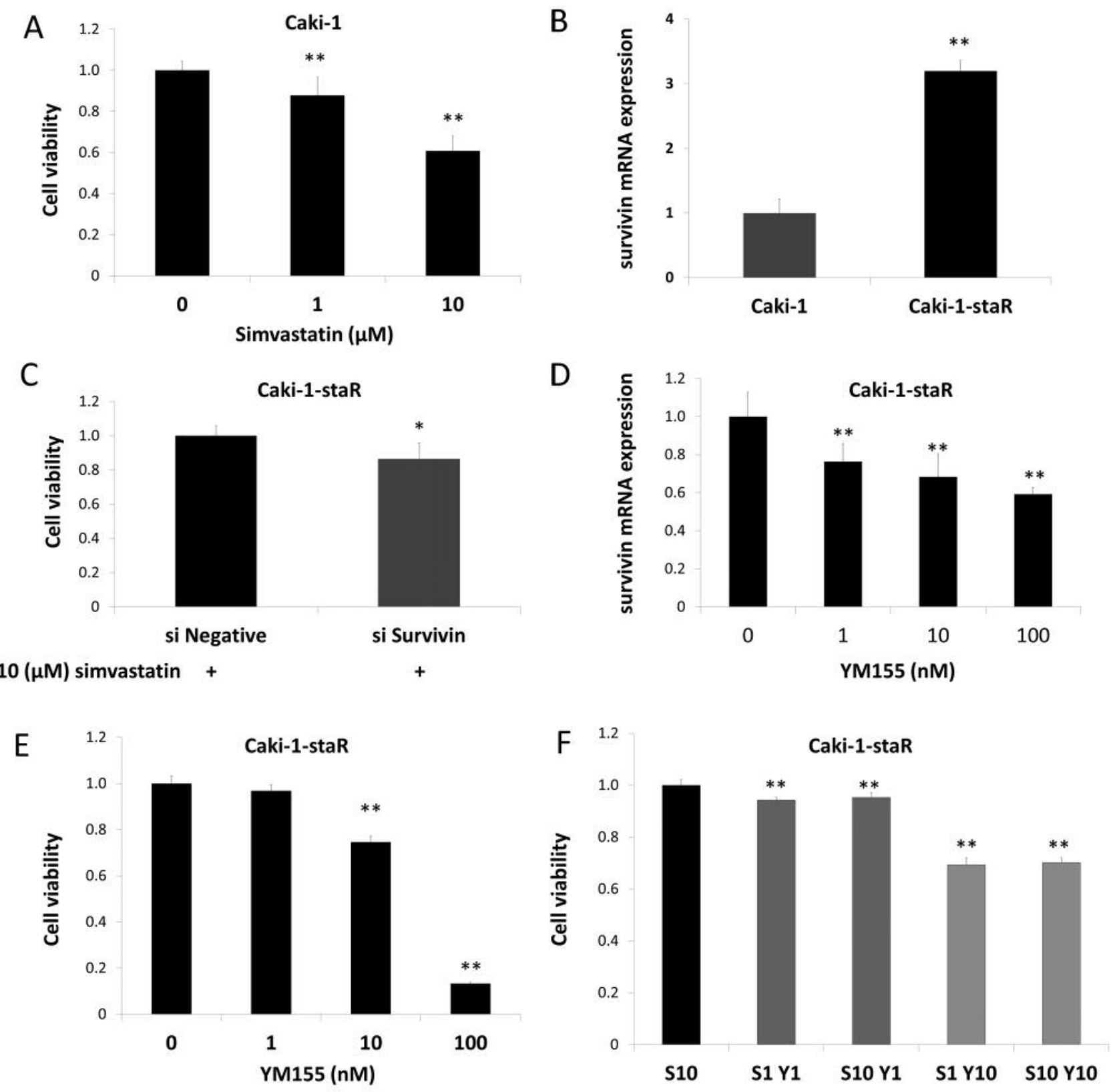

Figure 1. A: Caki-1 cells were treated for $48 \mathrm{~h}$ with simvastatin and the cell proliferation was assessed by the MTS assay. Values are expressed as the mean $\pm S D(n=5)$. ${ }^{* *} p<0.01$ versus the control. B: Survivin mRNA expression in Caki-1-staR cells and its parental cell line Caki-1 was examined by RT-PCR. Values are expressed as the mean $\pm S D(n=5) . * * p<0.01$ versus Caki-1 cells. C: Simvastatin-resistant Caki-1 cells (Caki-1-staR) with knockdown of survivin or treated with negative siRNA were then treated for $96 \mathrm{~h}$ with $10 \mu \mathrm{M}$ simvastatin, and cell proliferation was examined by the MTS assay. Values are expressed as the mean $\pm S D(n=6) .{ }^{*} p<0.05$ versus negative siRNA. D: Caki-1-staR cells were treated for $48 \mathrm{~h}$ with different doses of YM155 $(n M)$, and survivin expression was examined by RT-PCR. Values are expressed as the mean $\pm S D(n=5) . * * p<0.01$ versus the control, * $p<0.05$ versus the control. Caki-1-staR cells were treated for $48 \mathrm{~h}$ with YM155 alone $(E)$ or in combination $[Y(n M)]$ with simvastatin $[S(\mu M)](F)$ and cell proliferation was assessed by the MTS assay. Values are expressed as the mean $\pm S D(n=5)$. Significantly different at $* * p<0.01$ versus the control.

YM155 enhances the therapeutic effect of simvastatin in simvastatin-resistant renal cancer in vivo. Our in vitro data indicated that YM155 significantly reversed simvastatin resistance in renal cancer cells. Therefore, we administered
YM155 and simvastatin to a nude mouse xenograft model with Caki-1-staR cells. Simvastatin did not reduce tumor growth. On the other hand, YM155 significantly reduced the tumor burden (32\% inhibition by day 22). Treatment with 

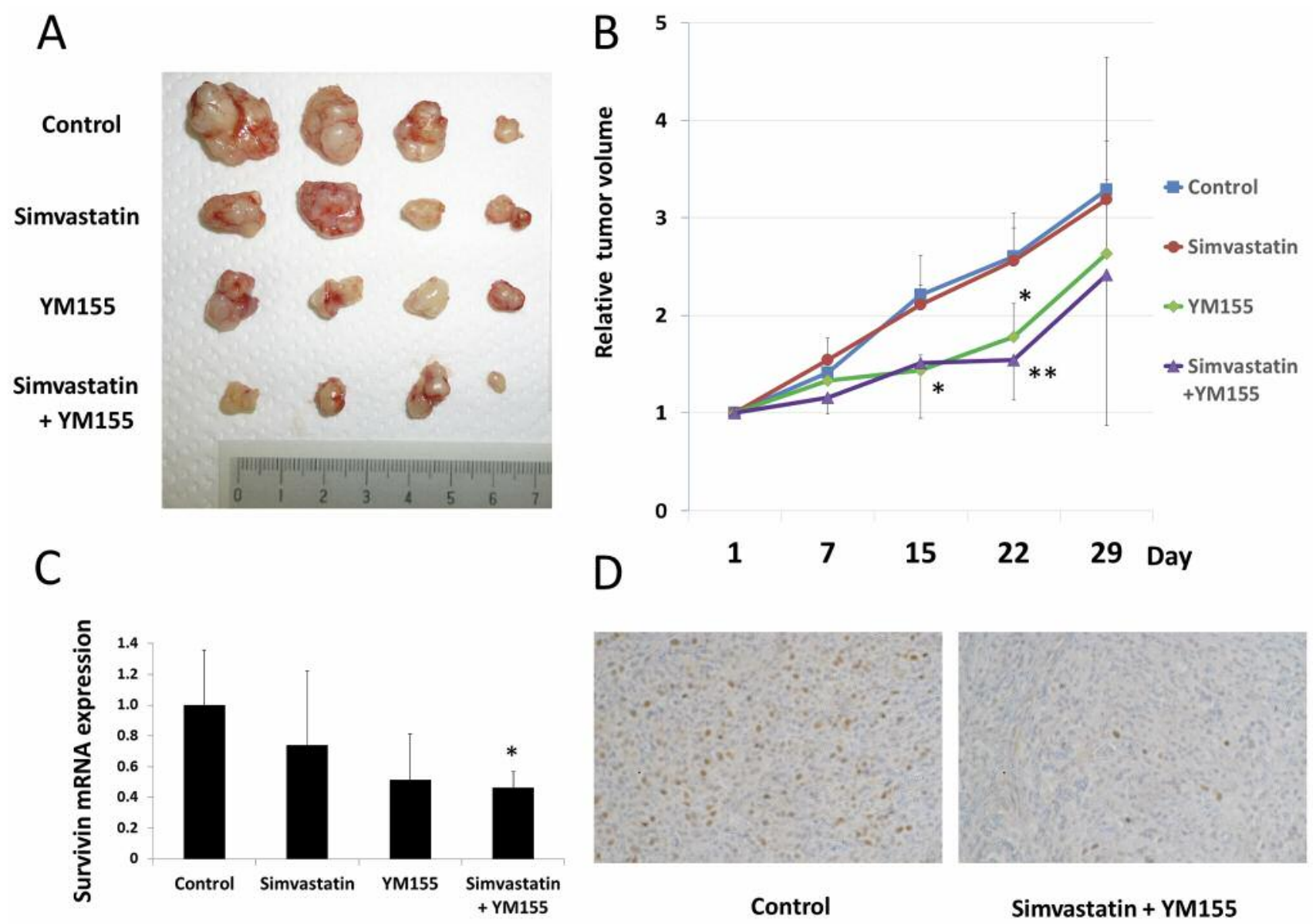

Figure 2. Animals bearing Caki-1-staR tumors were treated with YM155 (3 mg/kg) or simvastatin $(20 \mathrm{mg} / \mathrm{kg})$ alone or in combination or phosphatebuffered saline alone (control) every 3 days. A: Photographs of the Caki-1-staR tumors from untreated (control), simvastatin-, YM155-, or simvastatin- and YM155-treated groups of mice. B: Relative tumor volumes for Caki-1-staR tumors in mice treated with simvastatin, YM155, or simvastatin and YM155. Values are expressed as the mean $\pm S D(n=4)$. Significantly different at $* p<0.05$, and $* * p<0.01$ versus the control. $C$ : Survivin gene expression in Caki-staR tumors from mice treated with simvastatin, YM155, or simvastatin and YM155. Values are expressed as the mean $\pm S D$ $(n=4)$. Significantly different at ${ }^{*} p<0.05$ versus the control. D: Immunohistochemical staining of survivin in Caki-1-staR tumors.

YM155 and simvastatin was the most effective at inhibiting tumor growth (41\% inhibition by day 22) (Figure 2A and B).

YM155 tended to reduce survivin gene expression in Caki-1-staR tumors (49\% inhibition, $p=0.08)$. Treatment with YM155 and simvastatin significantly reduced survivin gene expression in Caki-1-staR tumors (54\% inhibition, $p=0.04$ ) (Figure 2C). Microscopically, there was more necrosis in the YM155-treated group or in the simvastatin and YM155 combination-treated group than in the control group and group treated with simvastatin only. The intensity of survivin staining of viable cells was strong in the control group. Although we were not able to evaluate the degree of the intensity exactly, the intensity of survivin staining of viable cells was weak in some mice in the YM155-treated group and in the simvastatin and YM155 combinationtreatmed group (Figure 2D).

\section{Discussion}

We studied the efficacy of YM155 and whether YM155 treatment could reverse simvastatin resistance in a simvastatinresistant renal clear cell carcinoma cell line, with acquired simvastatin resistance (Caki-1-staR), in vitro and in vivo.

Previous studies indicated an effect of statins against renal cancer. Khurana et al. investigated the relationship between statins and RCC in a case-control study of 500,000 veterans, and reported that the use of statins correlated with a risk reduction of $48 \%$ for RCC (32). However, one recent metaanalysis suggested that there was no association between statin use and the risk of renal cancer (33). Regarding the mechanisms underlying the anticancer effects of simvastatin in renal cancer in vitro, Fang et al. reported that simvastatin inhibited the protein kinase B (AKT)/mammalian target of 
rapamycin (mTOR), extracellular signal-regulated kinase (ERK), and Janus kinase 2 (JAK2)/signal transducer and activator of transcription 3 (STAT3) pathways (7). In the present study, we confirmed that simvastatin inhibited Caki1 cell proliferation in vitro. However, since the degree of anticancer effects of statin remains unclear, further studies are needed in order to investigate drug-resistant mechanisms. Therefore, we induced simvastatin resistance in a renal cancer cell line.

Among the mechanisms leading to resistance to statin treatment, we targeted survivin, an apoptosis inhibitor. We previously investigated survivin and its relationship with the role of 1a,25-dihydroxyvitamin D3 (1,25D) in prostate cancer cells, and examined the antitumor sensitization effects of survivin inhibition with a $1,25 \mathrm{D}$ treatment in hormoneresistant prostate cancer cells (34). In that study, under the transfection of siRNA against survivin, 1,25D inhibited the proliferation of the 1,25D-resistant prostate cancer cell line DU145. Accordingly, this treatment may become a therapeutic option as $1,25 \mathrm{D}$ therapy to remove the role of survivin in hormone-refractory prostate cancer. We also reported that the inhibition of survivin by YM155 reversed rapamycin resistance in renal cancer (31). In that study, YM155 significantly reduced survivin gene and protein expression levels and cell proliferation in a dose-dependent manner in a rapamycin-resistant renal cell carcinoma cell line (Caki-1-RapR). Furthermore, treatment with YM155 significantly reversed rapamycin resistance in cancer cells In a xenograft model, the growth of Caki-1-RapR tumors was significantly inhibited by YM155. Furthermore, YM155 significantly enhanced the antitumor effects of rapamycin in Caki-1-RapR tumors. These findings prompted us to confirm the effects of survivin inhibition in a statin-resistant renal cancer model. In the present study, the survivin mRNA level was higher in simvastatin-resistant cells than in their parental simvastatin-sensitive cells. Accordingly, we assumed that treatment that targeted survivin in statin-resistant renal cancer may enhance the therapeutic effects of statins by inhibiting the acquisition of chemoresistance. Furthermore, the knockdown of survivin by siRNA or YM155 in Caki-1staR cells significantly reversed simvastatin resistance in vitro. YM155 alone and the combination of YM155 and simvastatin also inhibited tumor growth by Caki-1-staR cells through the down-regulation of survivin in vivo. Kaneko et al. reported that the down-regulation of survivin by RNA interference induced apoptosis in a human colon cancer cell line, while its overexpression rendered cells resistant to lovastatin-induced growth inhibition (35). Our results are consistent with these findings.

In conclusion, we herein demonstrated that YM155 significantly enhanced the tumor-therapeutic efficacy of statin treatment. These results may provide novel strategies to reverse statin resistance in renal cancer.

\section{Acknowledgements}

The Authors thank Atsuko Oyama and Hayumi Oyama for providing technical assistance.

This work was supported by a Grant-in-Aid for Scientific Research (Project No. 25462467) from the Ministry of Education, Science, Sports and Culture of Japan.

\section{References}

1 Sanchez CA, Rodriguez E, Varela E, Zapata E, Paez A, Massó FA, Montaño LF and Lóopez-Marure R: Statin-induced inhibition of MCF-7 breast cancer cell proliferation is related to cell-cycle arrest and apoptotic and necrotic cell death mediated by an enhanced oxidative stress. Cancer Invest 26: 698-707, 2008.

2 Gopalan A, Yu W, Sanders BG and Kline K: Simvastatin inhibition of mevalonate pathway induces apoptosis in human breast cancer cells via activation of JNK/CHOP/DR5 signaling pathway. Cancer Lett 329(1): 9-16, 2012.

3 Kotamraju S, Williams CL and Kalyanaraman B: Statin-induced breast cancer cell death: role of inducible nitric oxide and arginase-dependent pathways. Cancer Res 67: 7386-7394, 2007.

4 Relja B, Meder F, Wilhelm K, Henrich D, Marzi I and Lehnert M: Simvastatin inhibits cell growth and induces apoptosis and $\mathrm{G}_{0} / \mathrm{G}_{1}$ cell-cycle arrest in hepatic cancer cells. Int $\mathrm{J}$ Mol Med 26: 735-741, 2010

5 Savas S, Azorsa DO, Jarjanazi H, Ibrahim-Zada I, Gonzales IM, Arora S, Henderson MC, Choi YH, Briollais L, Ozcelik H and Tuzmen S: NCI60 cancer cell line panel data and RNAi analysis help identify EAF2 as a modulator of simvastatin and lovastatin response in HCT-116 cells. PLoS One 6(4): e18306, 2011.

6 Cho SJ, Kim JS, Kim JM, Lee JY, Jung HC and Song IS: Simvastatin induces apoptosis in human colon cancer cells and in tumor xenografts, and attenuates colitis-associated colon cancer in mice. Int J Cancer 123: 951-957, 2008.

7 Fang Z, Tang Y, Fang J, Zhou Z, Xing Z, Guo Z, Guo X, Wang W, Jiao W, Xu Z and Liu Z: Simvastatin inhibits renal cancer cell growth and metastasis via AKT/mTOR, ERK and JAK2/STAT3 pathway. PLoS ONE 8(5): e62823, 2013.

8 Sekine Y, Furuya Y, Nishii M, Koike H, Matsui H and Suzuki K: Simvastatin inhibits the proliferation of human prostate cancer PC3 cells via down-regulation of the insulin-like growth factor 1 receptor. Biochem Biophys Res Commun 372(2): 356-361, 2008.

9 Altieri DC and Marchisio PC: Survivin apoptosis: an interloper between cell death and cell proliferation in cancer. Lab Invest 79: 1327-1333, 1999.

10 Zaffaroni N, Pennati M and Daidone MG: Survivin as a target for new anticancer interventions. J Cell Mol Med 9: 360-372, 2005.

11 Dong Y, Sui L, Watanabe Y, Sugimoto K and Tokuda M: Survivin expression in laryngeal squamous cell carcinomas and its prognostic implications. Anticancer Res 22: 2377-2383, 2002.

12 Sarela AI, Macadam RC, Farmery SM, Markham AF and Guillou PJ: Expression of the antiapoptosis gene, survivin, predicts death from recurrent colorectal carcinoma. Gut 46: 645-650, 2000.

13 Monzó M, Rosell R, Felip E, Astudillo J, Sánchez JJ, Maestre J, Martín C, Font A, Barnadas A and Abad A: A novel antiapoptosis gene: re-expression of survivin messenger RNA as a prognosis marker in non-small cell lung cancers. J Clin Oncol 17: 2100-2104, 1999. 
14 Asechi H, Hatano E, Nitta T, Tada M, Iwaisako K, Tamaki N, Nagata $H$, Narita M, Yanagida A, Ikai I and Uemoto S: Resistance to cisplatin-induced apoptosis via PI3K-dependent survivin expression in a rat hepatoma cell line. Int J Oncol 37: 89-96, 2010.

15 Chandele A, Prasad V, Jagtap JC, Shukla R and Shastry PR: Upregulation of survivin in $\mathrm{G}_{2} / \mathrm{M}$ cells and inhibition of caspase 9 activity enhances resistance in staurosporine-induced apoptosis. Neoplasia 6: 29-40, 2004.

16 Peng XH, Karna P, Cao Z, Jiang BH, Zhou M and Yang L: Cross-talk between epidermal growth factor receptor and hypoxia-inducible factor-1alpha signal pathways increases resistance to apoptosis by up-regulating survivin gene expression. J Biol Chem 281: 25903-25914, 2006.

17 Tirrò E, Consoli ML, Massimino M, Manzella L, Frasca F, Sciacca L, Vicari L, Stassi G, Messina L, Messina A and Vigneri P: Altered expression of c-IAP1, survivin, and Smac contributes to chemotherapy resistance in thyroid cancer cells. Cancer Res 66: 4263-4272, 2006.

18 Zaffaroni N, Pennati M, Colella G, Perego P, Supino R, Gatti L, Pilotti S, Zunino F and Daidone MG: Expression of the antiapoptotic gene survivin correlates with taxol resistance in human ovarian cancer. Cell Mol Life Sci 59: 1406-1412, 2002.

19 Morgillo F, Martinelli E, Troiani T, Orditura M, De Vita F and Ciardiello F: Antitumor activity of sorafenib in human cancer cell lines with acquired resistance to EGFR and VEGFR tyrosine kinase inhibitors. PLoS One 6: e28841, 2011.

20 Nakahara T, Kita A, Yamanaka K, Mori M, Amino N, Takeuchi M, Tominaga F, Hatakeyama S, Kinoyama I, Matsuhisa A, Kudoh M and Sasamata M: YM155, a novel small-molecule survivin suppressant, induces regression of established human hormone refractory prostate tumor xenografts. Cancer Res 67: 8014-8021, 2007.

21 Ryan BM, O'Donovan N and Duffy MJ: Survivin: a new target for anticancer therapy. Cancer treatment reviews 35: 553-562, 2009.

22 Cheng Q, Ling X, Haller A, Nakahara T, Yamanaka K, Kita A, Koutoku H, Takeuchi M, Brattain MG and Li F: Suppression of survivin promoter activity by YM155 involves disruption of Sp1-DNA interaction in the survivin core promoter. Int J Biochem Mol Biol 3: 179-197, 2012.

23 Kita A, Nakahara T, Yamanaka K, Nakano K, Nakata M, Mori M, Kaneko N, Koutoku H, Izumisawa N and Sasamata M: Antitumor effects of YM155, a novel survivin suppressant, against human aggressive non-Hodgkin lymphoma. Leuk Res 35: 787-792, 2011.

24 Nakahara T, Kita A, Yamanaka K, Mori M, Amino N, Takeuchi M, Tominaga F, Kinoyama I, Matsuhisa A, Kudou M and Sasamata M: Broad spectrum and potent antitumor activities of YM155, a novel small-molecule survivin suppressant, in a wide variety of human cancer cell lines and xenograft models. Cancer Sci 102: 614-621, 2011.

25 Yamanaka K, Nakahara T, Yamauchi T, Kita A, Takeuchi M, Kiyonaga F, Kaneko N and Sasamata M: Antitumor activity of YM155, a selective small-molecule survivin suppressant, alone and in combination with docetaxel in human malignant melanoma models. Clin Cancer Res 17: 5423-5431, 2011
26 Giaccone G, Zatloukal P, Roubec J, Floor K, Musil J, Kuta M, van Klaveren RJ, Chaudhary S, Gunther A and Shamsili S: Multicenter phase II trial of YM155, a small-molecule suppressor of survivin, in patients with advanced, refractory, non-small-cell lung cancer. J Clin Oncol 27: 4481-4486, 2009.

27 Lewis KD, Samlowski W, Ward J, Catlett J, Cranmer L, Kirkwood J, Lawson D, Whitman E and Gonzalez R: A multicenter phase II evaluation of the small molecule surviving suppressor YM155 in patients with unresectable stage III or IV melanoma. Invest New Drugs 29: 161-166, 2011.

28 Nakahara T, Yamanaka K, Hatakeyama S, Kita A, Takeuchi M, Kinoyama I, Matsuhisa A, Nakano K, Shishido T, Koutoku H and Sasamata M: YM155, a novel survivin suppressant, enhances taxane-induced apoptosis and tumor regression in a human Calu 6 lung cancer xenograft model. Anticancer Drugs 22: 454-462, 2011

29 Iwasa T, Okamoto I, Takezawa K, Yamanaka K, Nakahara T, Kita A, Koutoku H, Sasamata M, Hatashita E, Yamada Y, Kuwata K, Fukuoka M and Nakagawa K: Marked anti-tumour activity of the combination of YM155, a novel surviving suppressant, and platinum-based drugs. British journal of cancer 103: 36-42, 2010.

30 Na YS, Yang SJ, Kim SM, Jung KA, Moon JH, Shin JS, Yoon DH, Hong YS, Ryu MH, Lee JL, Lee JS and Kim TW: YM155 induces EGFR suppression in pancreatic cancer cells. PLoS One 7: e38625, 2012.

31 Koike H, Nitta T, Sekine Y, Arai S, Furuya Y, Nomura M, Matsui H, Shibata Y, Ito K, Oyama T and Suzuki K: YM155 reverses rapamycin resistance in renal cancer by decreasing survivin. J Cancer Res Clin Oncol 140(10): 1705-1713, 2014.

32 Khurana V, Caldito G and Ankem M: Statins might reduce risk of renal cell carcinoma in humans: case-control study of 500,000 veterans. Urology 71(1): 118-122, 2008.

33 Zhang XL, Liu M, Qian J, Zheng JH, Zhang XP, Guo CC, Geng J, Peng B, Che JP and Wu Y: Statin use and risk of kidney cancer: a meta-analysis of observational studies and randomized trials. Br J Clin Pharmacol 77(3): 458-465, 2014.

34 Koike H, Morikawa Y, Sekine Y, Matsui H, Shibata Y and Suzuki K: Survivin is associated with cell proliferation and has a role in 1a,25-dihydroxyvitamin D3 induced cell growth inhibition in prostate cancer. J Urol 185: 1497-1503, 2011.

35 Kaneko R, Tsuji N, Asanuma K, Tanabe H, Kobayashi D and Watanabe N: Survivin down-regulation plays a crucial role in 3hydroxy-3-methylglutaryl coenzyme A reductase inhibitorinduced apoptosis in cancer. J Biol Chem 282(27): 19273-19281, 2007.

Received November 12, 2016

Revised December 5, 2016

Accepted December 6, 2016 